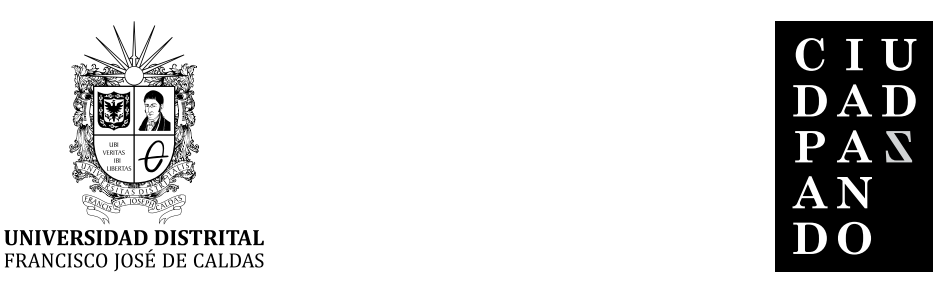

VOCES OTRAS

Artículo de investigación científica

\title{
Relato de una mujer abusada: huellas en la construcción subjetiva, del lazo social ${ }^{1}$
}

Story of an abused woman. Footprints in the subjective construction of the social bond História de uma mulher abusada. Pegadas na construção subjetiva na do vínculo social

\section{Jaime Velosa Forero ${ }^{2}$}

\section{Ana María Rojas Rondón ${ }^{3}$}

Para citar este artículo: Velosa, J., Rojas, A. (2017). "Relato de una mujer abusada: huellas en la construcción subjetiva, del lazo social”. Revista Ciudad Paz-ando, 10.1, 82-92

doi: https://doi.org/10.14483/2422278X.11288

Fecha de recepción: 28 de noviembre de 2016

Fecha de aceptación: 20 de junio de 2016

\footnotetext{
1 Resultado de la investigación “Violencia-familia-salud mental: características, percepciones, narrativas, Hospital Santa Clara E.S.E.”. Trabajo de grado para optar el título de psicóloga.

2 Psicólogo, Universidad Nacional de Colombia; magíster en Investigación en Problemas Sociales Contemporáneos, Universidad Central; clínico, docente, investigador en Hospital Santa Clara. E.S.E., Fundación Universitaria de Ciencias de la Salud., Fundación Aedificare. Correo electrónico: Velfor2@yahoo.com

3 Psicóloga Fundación Universitaria de Ciencias de la Salud. Especialista Docencia Universitaria Fundación Universitaria de Ciencias de la Salud Correo electrónico: Amrojas3@fucsalud.edu.co
} 


\section{RESUMEN}

La violencia pareciera estar siempre presente, tanto en la historia de la humanidad como en la de cada uno de nosotros. Este artículo, el cual hace parte de un trabajo sobre la violencia, aborda las marcas que esta deja en la subjetividad y en el lazo social. Basados en elementos conceptuales del psicoanálisis, se retoma el caso de una mujer abusada sexualmente en la infancia por su padre; se plantean interrogantes en torno a cómo repercute este hecho sobre su vida subjetiva, sobre su cuerpo y el lazo social. Finalmente, resalta lo importante que resulta el hecho de que la violencia sea escuchada, resignificada y reescrita en la historia personal, más aún en las circunstancias que vive Colombia.

Palabras claves: cuerpo, subjetividad, sujeto, violencia.

\section{ABSTRACT}

Violence seems to be always present, both in the history of humanity as well as in the history of every one of us. This article makes part of an extensive research on violence, addresses the marks violence leaves on subjectivity and the social bond. Based on conceptual elements of psychoanalysis, this study analyzes the case of a woman sexually abused in her childhood by her father. The article presents questions around how this fact affects her subjective life, her body and social bond. Finally, it highlights the importance of violence being heard, given new meaning, and re-written in personal history, even more so in the circumstances affecting Colombia.

Keywords: body, subject, subjectivity, violence.
A violência parece estar sempre presente, tanto na história e em cada um de nós. Este artigo é parte de um estudo sobre a violência, que aborda as marcas deixadas na subjetividade e laços sociais. Com base em elementos conceituais da psicanálise, o caso de uma mulher abusada sexualmente na infância por seu pai retomada. surgem questões sobre como este fato afeta em sua vida subjetiva, o seu corpo e o vínculo social. Finalmente, destaca-se o quanto é importante que a violência é ouvido, ressignificado e re-escrita história pessoal, mesmo em circunstâncias em Colômbia.

Palavras-chave: assunto, a violên, corpo, subjetividade. 


\section{Introducción}

Los casos de violencia, y en especial los casos de mujeres abusadas sexualmente, son tan repetidos -al menos en la consulta externa en el hospital-, que es imposible sustraerse y no plantearse preguntas frente a esta situación. Por una parte, moviliza el interés de comprender algo de esta realidad, por la otra, genera diferentes preguntas: ¿por qué tanta violencia sexual contra la mujer?, ¿cómo la violencia sexual afecta a la vida psíquica de la mujer?

Se promueven aún más interrogantes cuando se trata de casos de mujeres que siendo niñas fueron abusadas sexualmente por su propio padre, circunstancia dolorosa y difícil de comprender. Nuevas preguntas surgen allí: ¿qué pasa con esta mujer?, ¿cómo se ve afectada?, ¿qué significó el hecho de que su propio padre le obligue violentamente a tener relaciones sexuales?, ¿qué caminos, qué recorridos se toman para afrontar, asumir, evadir este hecho?, ¿qué relación tiene esto con sus formas de establecer lazo social?

El presente artículo recoge elementos de una historia planteada en el trabajo de entrevistas realizado a una mujer de 38 años — que llamaremos $D$ - que acude a consulta de psicología con un síntoma que, en principio, no parece estar relacionado con hechos de historia de violencia. En las entrevistas, la mujer describe cómo le afectó la violencia y en particular el abuso sexual infantil por parte del padre, así como sus características y sus huellas en la construcción subjetiva y en la manera en que hoy establece su lazo social, hecho sobre el cual se centra el trabajo. Algunas de las preguntas que orientan el caso son: ¿qué efectos deja en esta mujer el abuso sexual por parte de su padre?, ¿cómo se pone en evidencia su condición, lugar, función como mujer, madre y sujeto?, ¿cuáles son las huellas en su vida afectiva y sexual?

En primer lugar, el artículo esboza algunos elementos conceptuales y metodológicos, posteriormente, a partir de la construcción del trabajo investigativo, se resalta lo importante y lo significativo de la historia de vida de $D$, en particular en relación con las preguntas planteadas. Luego, desarrolla planteamientos teóricos en los que se revisan conceptos que se hace necesario precisar y, finalmente, plantea conclusiones y aportes.

Varios autores plantean lo traumático que resulta la experiencia de abuso sexual en la infancia y cómo este puede repercutir en el desarrollo psicosexual, afectivo y social de una persona, incluso cómo estas consecuencias permanecen y repercuten en la vida adulta (Reyes, 2012). (Soler 2014)

La problemática del abuso sexual en la infancia fue abordada por Freud en sus primeros trabajos, (Freud, 1895), primero como un evento traumático y luego en relación con la fantasía. Lacan $(1957 ; 1959)$ ubica el asunto de la experiencia traumática, si se quisiere llamar así, como un hecho de la palabra, del discurso, del cuerpo. $\mathrm{El}$ abuso es un asunto del lenguaje, una experiencia de discurso que dependerá de la manera como el acto sea significado, esto implica la manera particular como cada sujeto articula su relación con el saber, el deseo, y el Otro.

\section{Consideraciones teóricas}

\section{Sobre la violencia}

El abordaje de la violencia es amplio, diferentes enfoques y disciplinas se ocupan del tema, de modo que distintos aspectos de la violencia son abordados. El listado de contribuciones en el tema es cada vez más extenso;; la violencia se ha constituido en uno de los principales problemas, en objeto de múltiples estudios y en asunto central en la comprensión de la modernidad.

Nos interesará el tema de la violencia y lazo social y en particular - aunque no solo- desde una perspectiva psicoanalítica, en especial el pensamiento lacaniano; nos interesa la violencia visible, la cruel, aquella que se deja conocer y que tiene efectos -en el cuerpo o en la sociedad- que atrae la atención, pero también aquella invisibilizada, desconocida, que tiene múltiples relaciones con el sujeto y con las formas de establecer el lazo social.

En el caso particular, $D$ ha experimentado una violencia política pero también violencia en el campo de lo doméstico, violencia intrafamiliar y otras formas de violencia no tan visibles.

¿Y de qué se trata la violencia?, se ha entendido la violencia o, mejor, el acto violento, como el acto que se desarrolla basado en el abuso, el desequilibrio de poder y que se juega en el cuerpo del otro produciendo algún tipo de "daño" (físico y psicológico) sobre demás integrantes de un grupo (Molas, 2000).

Sin embargo, el término violencia puede tener una variada aplicación y su significación puede plantear otras perspectivas. Como se verá más adelante, la violencia es algo que pareciera ser característico, inherente a lo humano, así como una falla de lo simbólico o una salida ante algunas imposibilidades. Estos elementos, así como la naturaleza -y la génesis- de lo violento y sus nexos con la agresión o con el deseo son aspectos para revisar, conocer y reconocer.

Un recorrido por la obra de Lacan para explorar sus puntualizaciones sobre el concepto de violencia - que varios autores ya han realizado en diferentes sentidos: Castro (2006, pp. 41) — comienza con la advertencia de que la violencia no es una noción o un concepto central para

\footnotetext{
4 Se parte del trabajo de Velosa (2016) donde se realiza una revisión de trabajos sobre violencia, violencia en Colombia, sobre tipos de violencia y violencia - psicoanálisis. Se relacionan algunos de los documentos revisados sobre el tema violencia y que dan una primera aproximación general al tema: Ayala L. y Hernández K.K. 2012; Bolívar, I., González, F. y Vázquez, T. 2006; Castro M. C. 2006; Centro Nacional de Memoria Histórica, 2013; Jaramillo, J. 2011; Ortiz, S. Carlos; Mesa de trabajo mujer y conflicto armado, 2015.
} 
Lacan ni de su teoría; sin embargo, hay varias referencias y desarrollos en su obra en ese sentido, pues si bien no es una noción central siempre está presente. Vale la pena señalar que Lacan se ocupa del asunto en varios momentos, planteando la presencia de una tendencia agresiva como fundamento del yo y como base para el establecimiento del lazo social; en un plano estrictamente teórico psicoanalítico: Lacan plantea que para que el niño desee y demande debe ser violentado por el deseo del otro, en términos simbólicos y por medio del acto en términos reales, esto hará necesaria y posible la relación con el otro. Estos hechos hacen parte de una cadena donde aparecerá una violencia psíquica y sociopolítica más adelante.

Una vía para "el desciframiento" de la noción de violencia, señala Castro (2006), es que allí en el lugar donde precisamente abdica la palabra se inaugura el reino de la violencia, allí donde falla la palabra aparecería la violencia. Aunque también señala que la violencia hace presencia perenne y no requiere motivo para estar, siempre está, implícita y presente.

Ahora bien, Lacan también planteó que la palabra precisamente implica violencia, y plantea la distinción entre la violencia como acto y las huellas del significante. En ese orden de ideas, un acto de violencia deberá ser insertado como significante para que adquiera su poder y opere su marca imborrable; en otras palabras, deberá ser anudado como significante para que alcance un efecto estructurante en la constitución subjetiva. "Un síntoma es una significación [...] un significado que implica al sujeto, toda su historia, sus ancestros [...] Nunca es simple, siempre está sobre determinado. Del corazón de lo que está reprimido en el sujeto" (Lacan, 2003).

\section{Sobre sujeto, cuerpo y subjetividad}

La noción de sujeto aparece desde un principio en la obra de Lacan, si bien no claramente definida como noción si como un concepto ubicado como un elemento central de su elaboración:

[...]... el sujeto es fundamental en la demarcación epistémica del psicoanálisis...significa, en primera instancia, sujetado, alienado al Otro, al deseo del Otro, y por ello no se define, como en la psicología, por su autonomía. En segundo lugar, el sujeto está descentrado del yo que habla, no es ni el yo que habla, ni el yo que piensa, y aunque el yo está en escena, tampoco representa al sujeto, el cual le es desconocido. El yo no sabe sobre lo más íntimo, ni tampoco sobre las razones de las manifestaciones más externas de su personalidad. Desconoce tanto aquello que lo determina como la causa que lo hace sufrir y lo lleva a consulta. (Peláez, 2011, p.5).

Debe resaltarse que el sujeto de Lacan es un concepto que se separa del concepto empleado por otras disciplinas para referirse al ser humano, al individuo en términos generales. Lacan (1951) en "Algunas reflexiones sobre el yo" subraya la naturaleza simbólica de la representación de sujeto frente al carácter imaginario de lo que es el yo, constituido por toda una serie de identificaciones alienantes. El término sujeto no es el yo de la psicología; el sujeto no se explica, no se agota, no se equipará en el yo. La noción de sujeto no apunta al concepto de un yo consciente; más aún, el sujeto es el sujeto del inconsciente. Para Lacan el yo es producto de la imagen del otro, en lo que nombraba "estadio del espejo" (Lacan, 1949; 1966). "La experiencia de fragmentación del cuerpo por las pulsiones es superada por la cristalización de una imagen unificante, que pasa a tener peso de referencia, trayendo una vivencia de júbilo frente al reconocimiento de la propia imagen" (De Freitas, 2012, p. 120).

Para Lacan el sujeto se constituye por la suma de efectos del significante (que proviene de otro). El sujeto es lo que representa un significante para otro significante, el sujeto es efecto de la cadena significante. Es por la palabra que el sujeto aparece: el sujeto empieza en el lugar del otro, en tanto lugar donde surge el primer significante, como lo que representa un sujeto ante otro significante. Implica la dependencia, la sujeción al significante; así:

[...] el sujeto avanza en un recubrimiento imaginario de lo real, y a cada momento que la experiencia especular con el semejante se repite, el yo se consolida. Tiene lugar, entonces, la concepción de sujeto por la dirección de lo simbólico, marcado de manera inevitable por el lenguaje, alienado en lo significante. La castración instaura el sujeto segmentado, dividido, del lenguaje, del inconsciente, del deseo. (De Freitas, 2012, p. 120).

Lo que Lacan llamará "sujeto" es justamente esa construcción fundada en la palabra y el inconsciente (Lacan, 1973).

Lacan pone el acento en la oposición de dos campos, el del sujeto y el del Otro. El Otro como lugar donde se sitúa la cadena significante que rige todo lo que del sujeto podrá hacerse presente, en el campo de ese ser viviente donde el sujeto tiene que aparecer. El sujeto depende del significante para advenir y el significante está primero en el campo del Otro.

La noción de sujeto no es sustancia, logos, ni ser de conocimiento. Se disminuye así el ámbito del dominio y actuar conscientes del sujeto; no se trata ya de un sujeto consciente, en el cual se identifica todo lo psíquico con la instancia de la consciencia, sino que esta viene a ser solo una parte de lo psíquico, especie de fachada de una serie de procesos donde no está en dominio de lo que dice. De esta manera, asistimos a una relativización o rompimiento de la pretendida unidad del sujeto. La noción de sujeto, sujeto del inconsciente divide. 
De esta manera, la condición de sujeto es producto de la relación con el Otro, por el Otro y para el Otro; ese sujeto con la intermediación de los signos y símbolos culturales - que van conformando los vínculos sociales-y básicamente con la mediación del discurso, - -la forma particular de relación, la estructura que regula los vínculos moldea los actos y las fantasías- produce un lazo social peculiar, esto es: la condición de sujeto (la complejidad de la estructuración del psiquismo humano, el ser) y la forma de establecer lazo social, son producto de las relaciones con el Otro, los ideales, los vínculos sociales, etc.

En este caso ¿qué pasa con esa condición de sujeto y con esa forma de establecer relaciones (fantasías, deseos, relaciones) cuando se es una niña que es abusada sexualmente por su propio padre?

Revisaremos ahora las particularidades que separan y conectan los conceptos de sujeto y cuerpo; se partirá de la afirmación de que "no hay sujeto sin cuerpo" (Díaz, 2002, p. 23): hablar del cuerpo supone al mismo tiempo hablar del sujeto y su deseo. El cuerpo como noción subjetiva es el sostén material del sujeto en los diversos órdenes, otorga la imagen que representa al cuerpo y permite que se introduzcan sentidos sobre el cuerpo y el sujeto; el cuerpo soporta el nombre y la existencia del sujeto.

Se es del deseo del otro, diría Lacan, dándole así una gran importancia al otro y a su deseo a través de la palabra. Y si bien en Lacan el concepto de sujeto sufre trasformaciones, el sujeto es ese cuerpo, construcción simbólica, objeto de goce, deseo incesante, instaurado por el otro, a través de identificaciones, dividido, cuestión del inconsciente.

Así, existe una estrecha y particular relación con el cuerpo y lo subjetivo. Con un cuerpo no reductible al organismo por tratarse de un cuerpo representado, ordenado por el lenguaje:

"Los cambios corporales cobran estatuto de lenguaje, de escritura, donde el decir del sujeto se lee mucho mejor de lo que alcanzan a decirlo las palabras (a pesar de que son ellas quienes, por el contrario, intentan ocultar el decir del sujeto). El cuerpo habla del sujeto, lo representa. [...] Los cambios corporales como las alteraciones de la expresión facial, de las fluctuaciones en la distribución sanguínea en el organismo, de las secreciones, del estado excitativo de la musculatura lisa se producen bajo ciertas actividades psíquicas, como por ejemplo cuando se experimenta miedo, ira, dolor anímico, éxtasis sexual y otras emociones. De este modo, en el sonrojo, que es un fenómeno del cuerpo, el color rojizo que toma el rostro opera como significante de la ira o la vergüenza. El afecto llega al cuerpo que habita el lenguaje, indica Lacan, quien retoma la concepción freudiana de los afectos, la afina y replantea su fundamento económico." (Gómez, 2002, p. 74.).
En esta dimensión del cuerpo es evidente observar cómo las vivencias, experiencias - en cuanto valor significante- se inscriben, hacen marcas en el cuerpo.

\section{Sobre lazo social}

Se entenderá la expresión lazo social como la modalidad, la forma de establecer los vínculos humanos. Lacan construyó una teoría del discurso como fundamento del lazo social, como lo señala De castro:

[...]... lo que quiere decir, una estructura discursiva más allá de las palabras, que ordena el lazo entre los significantes y el lazo entre los cuerpos. Lacan formuló cuatro estructuras de discurso, nombradas en función del elemento que ocupa el lugar dominante, ellas son: discurso del amo, discurso de la histérica, discurso universitario y discurso del analista. (De Castro, 2012, p. 63) .

No obstante, Lacan (1991) planteó un nuevo discurso, el capitalista que, justamente, no es un discurso que haga lazo social. El discurso - como lo plantea Lacan- en tanto se dirige a otro, hace lazo social, es el lazo social. Es un dispositivo que propicia, como efecto propio de su funcionamiento, una relación, un vínculo colectivo.

¿Qué hace lazo social?:

[...]... el Lenguaje o más precisamente un cierto uso del lenguaje; aquel que tiene en cuenta al Otro, que se dirige al Otro y que pretende producir un efecto sobre este Otro: efecto de dominación, de influencia, de sumisión, de persuasión, de enseñanza, de trasmisión, de sugestión, de seducción, etc. (Askofare, 2012, p. 153).

en segundo lugarTambién la identificación, que determina, por una parte, el ser sujeto, y por otra, el ser social; esto último a través de la religión, la cultura, la lengua y la política.

\section{Acerca de lo metodológico}

La investigación se establece dentro de la línea de investigación principal que se ha venido desarrollando: violencia, familia, salud mental, y se centró particularmente en la forma como es narrada y representada la violencia por un grupo de personas que acuden a consulta externa en la unidad de salud mental del hospital Santa Clara E.S.E. Bogotá D.C. 2015-2016.

En el hospital se entrevistaron 60 pacientes que referían ser víctimas de violencia; de este grupo de entrevistados se tomó una paciente, cuya selección fue por conveniencia, oportunidad y disponibilidad, en tanto se ajustaba a los parámetros planteados en la investigación. Se realizó un estudio de caso a partir de sus relatos y se siguieron los lineamientos planteados por la teoría psicoanalítica lacaniana, que dice que este se formula y se 
presenta para articular elementos teóricos, trabajar sobre el decir del paciente y articular el caso con la clínica (Berenguer, 2006; Laurent, 2007).

Durante las sesiones la paciente relató y escribió su vida, así como los hechos y los eventos de violencia, y para su registro los investigadores digitalizaron la historia. $D$ asistió a sesiones durante seis meses (veinte sesiones, a razón de una sesión semanal), entrevistas psicoanalíticas abiertas y a profundidad; asimismo, se organizaron, depuraron y analizaron los fragmentos tomados de la historia de vida para responder a las preguntas planteadas en el presente artículo.

El presente trabajo, si bien se puede considerar como una investigación cualitativa en tanto, como lo menciona (Fernández y Díaz, 2002, p. 2) "no se centra en la cuantificación. Los investigadores cualitativos hacen registros narrativos de los fenómenos que son estudiados mediante técnicas como la observación participante y las entrevistas no estructuradas". Es decir que la investigación cualitativa estudia contextos estructurales y situacionales. "La investigación cualitativa trata de identificar la naturaleza profunda de las realidades, su sistema de relaciones y su estructura dinámica” (Fernández y Díaz, 2002, p. 2).

Varios autores como Bueno, Osawa y Rodríguez (2006) plantean la entrevista psicoanalítica como una herramienta que nos daría la posibilidad de acceder a contenidos inconscientes. El discurso libre, se sabe, no es tan libre como parece; existe una relación entre los temas que van saliendo a la luz cuando se asocia libremente.

De hecho, el relato siempre ha estado en el psicoanálisis. Freud, en particular introduce permanentemente fragmentos, narraciones, viñetas de sus casos en sus trabajos teóricos y clínicos; de hecho, en muchos de sus trabajos argumenta, ejemplifica y recrea sus elaboraciones con relatos y algunos de sus casos son especialmente reconocidos por su relato: Estudios sobre la histeria, La interpretación de los sueños, Psicopatología de la vida cotidiana, Fragmento de análisis de un caso de histeria (Caso Dora), Análisis de la fobia de un niño de cinco años, A propósito de un caso de neurosis obsesiva, De la historia de una neurosis infantil, caso del "hombre de los lobos".

Freud planteó en El delirio y los sueños en la "Gradiva" de W. Jensen, y en El creador literario y en el fantaseo (Freud, 1908a; 1908b), que la novela, la novela familiar de los neuróticos o la fantasía novelada y finalmente la realidad interpretada, está en estrecha relación con los deseos y el inconsciente del soñador y de su vida psíquica.

Así, pues, las pequeñas historias son parte integrante de la doctrina analítica; cada una contiene una lección a cosechar como conviene a cada uno (Laurent, 2007). Los relatos sirven para construir realidades. Una de las cualidades del relato es que, aunque hace ver, muestra y no dice, no se puede extraer una conclusión; siempre hay alguien que ve, un testigo que ve y cuenta, hace circular lo visto. Siguiendo lo anterior, "el psicoanálisis considera al texto como un lugar de encuentro donde trabajan tanto el inconsciente del autor como del lector" (Piglia, 1997).

El relato es entonces un texto narrado sesión tras sesión que va configurando la historia de vida, una historia marcada por eventos particularmente especiales. Blumer señala que:

[...]... los seres humanos actuamos a partir del significado que las cosas o eventos tengan para nosotros. En la historia de vida se recogen aquellos eventos de la vida de las personas que son dados a partir del significado que tengan los fenómenos y experiencias que estas vayan formando a partir de aquello que han percibido como una manera de apreciar su propia vida, su mundo, su yo, y su realidad social. (Blumer, 1969, p. 65 citado por , en Charriez, 2012, p. 50-67).

Estos relatos se sometieron a varias lecturas, a discusiones y reflexiones y se planteó el presente texto, que intenta tejer y articular los relatos con los planteamientos teóricos que orientaron el trabajo y que por meses guiaron las lecturas y reflexiones; y que parten de conceptos como sujeto, inconsciente, lazo social, violencia, huella. Finalmente, se plantean algunos aportes y conclusiones.

\section{Relato}

\section{Caso D}

$D$ es una mujer de 38 años que nació en zona rural de un municipio del departamento de Boyacá, donde fue abandona por sus padres y criada por su abuela materna. Lleva veinticuatro años viviendo en Bogotá D.C., tiene dos hijas de quince y diecisiete años y un compañero sentimental desde hace siete años. $D$ trabaja en zapatería, vive en arriendo y depende económicamente de su trabajo, de su pareja y recibe una ayuda humanitaria por parte de la Unidad de Atención y Reparación para las Víctimas.

Luego de ser abandonada por sus padres, fue víctima de violencia sexual infantil por parte de su padre. Posteriormente, se convirtió en una víctima más de la violencia intrafamiliar (física, psicológica y especialmente sexual); después llegó a un pueblo donde hizo parte de las autodefensas y años después se incorporó a la guerrilla, para sostener a sus hijas. Actualmente, $D$ se presenta como víctima y desmovilizada de la guerrilla. Refiere que la violencia que más le dejó huellas, marcas y dificultades es la violencia sexual, por parte del padre.

$D$ asiste a consulta de psicología porque:

"La doctora del hospital me remitió, llevo tres años con un dolor allá. Y me han dado de todo y no se me quita; no me gusta estar con los hombres. Tuve un inconveniente a los once años, por eso la doctora me remitió. Pues como en el campo no le hablaron a uno del periodo 
y las relaciones sexuales. No me gusta hablar de eso, lo que hizo mi papá conmigo (llanto); yo siempre he querido hablar de eso.

Mi papá ha sido el infierno que nunca quise conocer, de pronto a mi mamá no la juzgo mucho, pero a mi papá es lo peor que me ha pasado en la vida, yo cuando conocí a mi papá tenía siete años, fue feo cuando lo conocí, un día él llegó y no sabía quién era ese señor, andábamos cochinos, descalzos, el me llamó por mi nombre y yo salí corriendo, y le dije a mi abuela y ella nos arregló, nos bañó, nos colocó ropa, zapatos y me sacaron al patio y ella nos dijo que ese señor era mi papá, en mi mente tenía que mi tío materno era mi papá, a mi abuela materna siempre le dije mi mamita para todo, mi tío era mi papá y mi abuela era mi mamá. Mi papá nos llevaba muchas galguerías y pues uno de niño eso le gusta, él comenzó a ir, ese año iba seguido y yo me encariñe a él, pero era por las galguerías, decirle a él papá era duro, porque yo le decía papá a mi tío.

Desde los once años me tocó vivir con mi abuela paterna y con mi hermano y la familia de mi papá, haber llegado a esa casa fue mi peor tormento. Donde mi abuela me tocó vivir un infierno que nunca más viví, allá no había baños y me tocaba hacer cerca de las matas y él siempre me veía, el siempre que me abrazaba, me tocaba los senos, yo sabía que algo malo pasaba, yo sentía que lo que él hacía estaba mal, pero nunca imaginé que tan malo fuera, así pasaron los días, los meses, incluso hasta los años, cada vez que iban a la casa traían cerveza, y se emborrachaban, mi abuela, mi papá y mi tío, no sé actualmente si toma, pero no quiero saber nada de esa gente.

Yo dormía en la misma habitación y en la misma cama con mi hermano, y un día mi abuela se llevó a mi hermano a dormir con ella y cuando me desperté quien estaba al lado mío era mi papá, ¿Por qué me desperté?, porque mi papá me estaba cogiendo los senos; él me cogía y me decía que si decía algo me venían cosas peores, yo sentí miedo y asco porque estaba untada de semen, al otro día yo no dije nada.

“...Un día íbamos caminando por un pedazo de la finca que era de mi abuela y mi papá me dijo que él tenía que enseñarme cómo se hacían los hijos, y se quitó la ruana y la extendió en el piso. Un día yo no me quería quedar dormida, pero el sueño me ganó, ese día volvió a pasar lo mismo: mi hermano no estaba a mi lado, él me tapó la boca y me dijo que no gritara o si no me hacía algo o le hacía daño a mi hermano, y otra vez estuvo conmigo, yo quería salir corriendo y él me dijo que tenía que hacerlo, porque era obligación de él enseñarme cómo se hacían los hijos. Al otro día le dije a una tía y me dijo que eso era normal, que eso le tocaba pasar por ahí a todas las mujeres; yo me quería morir, yo no quería seguir viviendo, sentía asco.

“...De ahí en adelante el hacía lo que quería conmigo, él venía a Bogotá supuestamente a trabajar, pero él iba todos los sábados a visitarnos, yo le conté a mi hermano, y él me decía espere yo comienzo a trabajar y la saco de aquí. El día que lo enfrenté con mi familia, mi hermano no me apoyo, él se quedó callado, todos me pegaban y decían que yo era una chismosa. Mi papá abusó de mí como desde los doce años como hasta que cumplí quince años. Yo muchas veces intenté matarlo, mi hermano no podía hacer nada por mí porque él lo cogía y le pegaba, yo nunca callé lo que él me hacía, así él me pegara yo nunca me quedaba callada, eso siempre lo hacía en las tardes, yo sentía mucha rabia, yo comencé a llenarme de rabia y de venganza, yo siempre quise tener una pistola y poderlo matar. Al ver que en mi familia nadie me puso cuidado, primero cogí la calle y después busqué trabajo en una casa de familia, no fue fácil.

“...Un día llegó mi papá, me quitó toda la ropa y estuvo conmigo y después de que hizo eso me pegó y me arrastró por el patio y me metió en la alberca, yo le tengo miedo a las albercas, no puedo meter las manos a una alberca porque siento mucho miedo, el conectó el encendedor de la estufa a la alberca y decía que a las perras las tenía que meter ahí para que no quedaran en embarazo. Un día me metió desnuda en un baño y me encerró, mi hermano llamó a una tía que vivía en el norte y ella llegó con la policía y rompieron el candado me subieron al carro de la policía me llevaron a medicina legal y me sacaron exámenes y ella se dio cuenta que todo lo que yo había dicho era verdad, y se dieron cuenta de todo, yo tenía como catorce o quince años.

Mi tía me dijo que me iba a ayudar, ella fue la persona que yo más quise, ella me prometió que me iba a ayudar: llamaron a mi papá y le dijeron que como yo no tenía mamá que firmara la salida para salir del país, ella le dijo a mi papá que me firmara, que ya que nadie se quería hacer cargo de mí, ella lo iba a hacer, mi tía le dio las escrituras de la finca y le dijo que yo cuánto valía, ella le dijo a mi papá que me llevaba pero que me cambiaba el nombre, yo le dije a mi papá que no lo denunciaba pero que me dejara ir con ella, yo creía que ella era mi mamá, yo dormía con ella, me compraba cosas, me enseñó cosas bonitas. Mi papá le dijo que prefería verme en la calle. Mi papá declaró que yo inventaba, que yo lo calumniaba, que yo lo quería meter preso. Después yo me fui a la calle y después como prostituta, allá me maquillaron, me pusieron ropa, yo me sentí sucia, el primer cliente que me llegó fue un viejo igual a mi papá: la misma estatura calvo y borracho y él llegó, me trató mal y yo me quité el tacón que me habían puesto y se lo rompí en la cabeza, me echaron y me tocó irme.

“...Lo de mi papá es lo que más me afecta, yo quiero dejar eso, olvidarme de todo eso, de todas las cochinadas que él hacía conmigo. Yo quiero matarlo, no quiero que se acerque a mis hijas, si yo hago eso me quito eso que hay aquí en el corazón, tengo rabia con mi papá, conmigo también hay rabia porque no me supe defender, yo estaba entre los once y doce años cuando empezó a pasar eso, 
yo lloraba quería irme de la casa, quería morirme, no quería seguir viviendo, me sentía sucia, sentí que olía a feo porque a mí nunca me habían hablado de eso, de sexo, me daba asco.

“...Recordar a mi papá me afecta cuando voy a tener relaciones, por la forma como me coge mi esposo, me da rabia, las palabras que me decía, la mayoría de las personas con las que he estado me recuerdan a mi papá, a veces voy por la calle y me encuentro con una persona que se parezca a mi papá y me da miedo, no entiendo, siento miedo que él sea, yo pienso que cualquier señor podría ser él.

“...Es horrible vivir con un recuerdo de esos, yo no recuerdo porque es doloroso, siento culpa, yo siento rabia me da pena, asco, y me siento culpable de haberme salido de la casa de mi abuela, pero en parte yo sí quise salir, es que mi tío y mi tía nos pegaban mucho.

Yo me encariñe de él por las galguerías, porque pensé que de pronto era bueno, cuando él iba de visita mi abuela le servía el almuerzo y comíamos en el mismo plato, después yo ya no me le acercaba, yo sentía miedo antes de que él me hiciera algo, yo sentía como desconfianza hacia a él, como si sintiera que él me hiciera eso, cuando estaba donde mi otra abuela no lo sentía. Mi tía, una hermana de él, me decía que tuviera cuidado de él, no sé por qué, yo pensé que era cuidado de que él comiera bien, viviera bien, que le lavara la ropa. Ella una vez que fue de visita me dijo que me saliera de esa casa. Yo digo que es muy doloroso que un papá haga eso con uno.

Yo quisiera olvidarme de todo esto, pero lo que más rabia me daba es tomarme fotos, yo me tomo fotos y me quedo pareciéndome a alguno de los dos y no me gusta."

D relata eventos de enorme violencia, pues convivió con paramilitares primero y con la guerrilla después y allí vio e hizo parte de masacres, fue perseguida. También relata eventos de gran violencia y maltrato por parte de algunas de sus parejas, sin embargo, su tema central, el que le afecta, es la violencia infligida por su padre.

"Una marca fue lo que hizo mi papá conmigo, hasta el día de hoy no la he superado, pensé que en un momento de mi vida la iba a superar, pero no, sin embargo, el tratamiento que llevo en psicología me ha ayudado a asimilar que fue algo que pasó y que debe quedar atrás...aún hay cosas que me siguen martillando, cuando veo noticias sobre abusos siento mucha rabia, ese monstruo no se ha ido de mi vida, porque yo quisiera coger todos esos violadores y matarlos. Dentro de mí hay rabia, resentimiento, un odio contra él que ni yo misma se cómo acabarlo, con solo verlo me da asco y el cuerpo me empieza a temblar y vuelvo atrás.

Yo empecé a saber que era un abuso cuando salí de la finca y conocí la ciudad, aquí me enseñaron y lo aprendí con los de la calle, y ellos me preguntaron un día, porque había cogido la calle, le dije que por mi papá, yo veía eso feo, como un maltrato, pero no sabía que eso se llamaba sexo en esa época no sabía que las partes del hombre se llamaba pene y las de la mujer vagina, y él se sentó y me dijo ¿su papa abusa de usted? y yo le dije ¿eso qué es? Y él se sentó y me explicó todo: me dijo que él abusaba de mí... quien me explicó fue mi amigo el de la calle. Me llené de rabia y comencé a pensar en conseguir un arma y en matar a mi papá; he visto cómo ese odio y ese rencor lo tiene mi hija grande... yo tengo odio rencor, resentimiento.

“...He mejorado mucho, llevo un mes prácticamente que ese dolor es prueba superada... Antes me sentía triste, aburrida, trabajaba porque me tocaba, ahora ya lo hago porque me gusta. La relación con mis hijas ha mejorado mucho...la vida me ha ido cambiando, veo mi cuerpo diferente, ha cambiado, ya me dan ganas de arreglarme, ya veo diferente los días, para mí los días eran oscuros, ahora creo que la vida es bonita....ahora tengo una familia, siempre quise tener una familia...yo nunca quise que mi historia se volviera a repetir, por eso cuido mucho a mis hijas."

\section{Análisis y discusión}

A partir del relatoSe parte del relato de quien se presenta en un momento como víctima de violencia, relata efectos clínicos que atraviesan sus formas de establecer relaciones. Su dolor "allá", la dificultad para tener relaciones sexuales, el rechazo y desinterés frente a la sexualidad. También la presencia de miedos para establecer o sostener la relación con los otros, en especial con los hombres, al compartir, a ser vista; la instalación de temores, la presencia de estados de apatía y de tristeza que la han conducido a aislamientos o separaciones durante cierto tiempo. Asimismo, la manifestación del sentimiento de intensa rabia, que llega incluso a ideas de muerte, a veces seguida de actos radicales y a la colocación en actos de fantasías sexuales, entre muchas, pero especialmente la sensación permanente de ser víctima y la sensación de sufrimiento. Debe resaltarse que, si bien se presenta como víctima, ella misma ha ejercido la violencia de múltiples maneras, sus relatos, sus deseos y fantasías así lo evidencian.

Para nuestra reflexión tomamos un término que usa Lacan (1938) en el artículo sobre la Los complejos familiares en la formación del individuo, él habla de la declinación social del imago paterno, lo cual constituye un elemento clave para poner la cuestión de la ley y la autoridad. Esta formulación de Lacan apunta a que el mundo de los valores, de los ideales, de los grandes relatos, de los fundamentos, ya no tiene vida, ha caído. De algún modo se puede decir que el siglo XX es un siglo de declinación de ideales, de valores y de la autoridad. Nosotros también hemos asistido a esta declinación y evidentemente $D$ de igual forma. Por otro lado, Freud (1920) plantea que una 
blandura del ideal del yo, así como el declinar de los ideales provoca una disgregación y grandes dificultades en la regulación.

Ya centrados en $D$, nos preguntamos ¿cómo la violencia sexual por parte de su padre le afectó?, ¿qué significó que su padre la haya obligado a tener relaciones sexuales?, ¿qué efectos tuvo en la manera como se percibe, se relaciona y como asume su vida como mujer y madre?, ¿cuál es la relación entre estos eventos y sus síntomas? Finalmente, ¿cómo $D$ afronta y supera esas huellas que dejó en ella aquel evento traumático? $D$ responde por sí sola estas preguntas.

La violencia es sostenida en gran parte por la cultura; en este caso, se concibe al hombre como autorizado a ejercer poder y abusar del otro vulnerable. La mujer no es reconocida, es borrada, anulada como sujeto. La violencia recae sobre el más débil, el más frágil; hay un abuso del poder del padre. El padre de $D$ es un papá que transgrede los límites y esto es validado por el contexto. La tía considera esto "normal", la abuela y otros parecen cómplices de esta situación tan violenta, se trata de un mundo donde los padres abusan de sus hijas, les enseñan cómo se hacen los hijos y es eso normal.

Cuando $D$ es víctima de violencia no considera exactamente esos hechos como violentos, o no con el valor que luego tendrá, sin embargo, después la reconoce como un acto doloroso y se instaura como una huella que marcará su vida. Esto es importante considerarlo; este acto violento le afecta su condición de sujeto, y en sus representaciones de lo que constituye el ser mujer, ser madre, ser pareja.

Una de las formas de superar y afrontar esas huellas que dejó el evento traumático es evadiendo, reprimiendo, huyendo física y psíquicamente (somatizando o a través de inhibiciones y síntomas). Finalmente, asistió a consulta de psicología que, como ella lo señala, le trae cambios y alivios, lo cual es algo importante.

\section{El traumatismo como goce del otro}

$D$ consulta al médico por su dolor "allá", que pronto se relaciona con su dificultad y malestar en su vida sexual y que claramente se relaciona con los eventos vivenciados con el padre.

Las sensaciones de estar invadida por los recuerdos del abuso sexual cometido por el padre son revividas por el proceso de trabajo clínico; esta situación, insoportable en ocasiones, reaparece en forma de síntomas, activada por las dificultades en su vida sexual. La particularidad de este momento, siguiendo a Lacan (1962), es la emergencia de un goce "en exceso", del otro que mortifica al sujeto, reduciéndolo a su posición de objeto. Ella aún queda reducida a la función de puro objeto de satisfacción del padre; en algunos aspectos de su vida continúa atrapada (en su vida subjetiva, inconsciente) en su relación con el padre.
Aunque se trate de una experiencia que le molesta - "me daba asco"-, en ella predomina una articulación significante que intenta ordenar inicialmente sin considerar su valor sexual o de abuso. Entonces se puede apreciar el fracaso por mantener el deseo del otro "enmarcado" y "alejado" por sus límites; así, la dimensión del traumatismo aparece como fracaso del fantasma por "ordenar" y distanciar el goce del otro, este periodo del trabajo es denominado "los recuerdos", que, si bien en un inicio corresponde a exponer su síntoma ante el terapeuta, dará paso a una nueva forma de relación con los recuerdos, poner palabras donde no las había, donde el relato se detiene. De este modo, el sujeto comienza a dar el paso a una narrativa diferente, el relato se complejizará, dando lugar en la historia a cada uno de los integrantes de la familia y a ella misma. Los recuerdos serán vinculados con sus experiencias actuales. Aparecerá el abuso, el dolor, el traumatismo.

\section{El otro masculino como el abusador}

Podemos describir una trayectoria respecto de quién es el padre para la paciente, que le permitirá situarse en relación al deseo del otro. El padre aparece siempre del lado del poder, de la omnipotencia, por lo tanto, se introduce un cuestionamiento respecto de la posición del padre; ella agregará que él es una persona violenta y ante la cual no se puede decir ni hacer nada. Estos significantes permitirán hacer más clara su relación con él y con quienes lo representan; esos otros serán potenciales objetos de deseo a la vez que potenciales abusadores.

\section{El S (sujeto) como víctima}

Podemos señalar que se produce un recorrido que va desde una indeterminación subjetiva hasta persistir como el objeto de otro; así, ella refiere que al principio no sabe qué lugar ocupa en el deseo del otro, no hay ningún significante que dé cuenta de esa posición. Digamos que no se siente deseada ni abusada exactamente; será luego, años después de que se instalara como la víctima, la abusada y que ligara hombres con deseo sexual y esto con abuso y con malestar o miedo a ser víctima.

\section{Ideas y aportes}

$D$ solicito ser escuchada. La violencia reclama pasar por otros registros, ser contada, narrada, resignificada, simbolizada. Escuchar más allá de un diagnóstico y de unos síntomas y también más allá del juicio o las consideraciones morales.

La violencia está al inicio, en la dinámica familiar y social más próxima. Los padres abandonan, abuelos y tíos encubren el delito y la atrocidad del padre. Muchos salen huyendo de esta violencia. Primero apareció una violencia familiar, parental; después, quizá como parte de esa cadena no visible, aparecen otras formas de violencia. $\mathrm{Y}$ es que la violencia, contrario a lo que se supone, no es 
de otros, no es ajena, es absolutamente cercana, aparece en primer lugar con los más próximos.

Luego ella misma es quien ejerce la violencia, dentro de esa cadena de repetición, por una parte con sus hijas, parejas y especialmente consigo misma, pero también como actora y parte del conflicto armado en nuestro país.

La violencia - tan cercana y tan presente- es a veces desconocida, no reconocida; sin embargo, está ahí y está primero. Es importante considerarla, abordarla, resulta especialmente significativo escucharla revelar su carácter aniquilador, destructivo, trágico.

Así, la violencia es representa y constituida a partir de las vivencias propias que están ligadas con su historia, pues la violencia deja huellas, marca y dificultades en la forma de asumir ser sujeto, en las relaciones con otros, es decir en el establecimiento del lazo social. Para el ser humano, entonces la relación con el otro es inherente y esta relación es a través del lenguaje y en esa medida aparece la violencia.

\section{Referencias}

Askofare, S. (2012). La puesta en juego de la exclusión. En G. Gómez, (Ed.). Clínica del sujeto y del lazo social. Bogotá, D.C. Gloria Gómez, Ediciones.

Ayala, L., y Hernández, K. (2012). La violencia hacia la mujer. Antecedentes y aspectos teóricos. Recuperado de http://www.eumed. net/rev/cccss/20/ashm.pdf

Bolívar, I; González, F; Vázquez, T. (2006). Violencia politica en Colombia. De la Nación fragmentada a la construcción del Estado. Bogotá, D.C.: Centro de Investigación y Educación Popular, CINEP.

Blumer, H. (1969). Symbolic Interactionism: Perspective and method. Nueva Jersey: Prentice Hall.

Bueno, R., y Rodríguez, S. (2006). La entrevista psicoanalitica; una herramienta de investigación cualitativa. Fepal-XXVI Congreso Latinoamericano de Psicoanálisis "El legado de Freud a 150 años de su nacimiento". Lima. Recuperado de http://fepal.org/images/2006invest/bueno\%20osawa_rosalba.pdf.

Castro, M. (2006). Transgresión, goce y profanación. Contribuciones desde el psicoanálisis al estudio de la violencia y la guerra. En Centro nacional de Memoria Histórica (Ed.). Informe. Basta ya. Colombia: Memorias de Guerra y Dignidad.

De Castro, S. (2012). Síntoma y discurso: las enseñanzas de "La moral sexual 'cultural' y la nerviosidad moderna. Universitas Psychologica, 11(2), 631-644.

De Freitas, A. (2012). Sobre la concepción de sujeto en Freud y Lacan. Alternativas en psicología. Revista semestral. Tercera época, 16(27), 120.

Díaz, C. (2002). Destrucción del cuerpo: de la fantasía al acto. Desde el jardin de Freud, Número 2, 2002 págs. 20-37.

Fernández, P. y Díaz, P. (2002). Investigación cuantitativa y cualitativa. Unidad de Epidemiología Clínica y Bioestadística. Complexo Hospitalario Universitario Universitario de A Coruña (España). Recuperado: http://www.fisterra.com/mbe/investiga/cuanti_ cuali/cuanti_cuali.a
Freud, S. (1895). Estudios sobre la histeria. [Obras completas]. Buenos Aires: Amorrortu.

Freud, S. (1908a). El delirio y los sueños en la "Gradiva" de W. Jensen. [Obras completas]. Buenos Aires: Amorrortu.

Freud, S. (1908b). El creador literario y el fantaseo. [Obras completas]. Buenos Aires: Amorrortu.

Freud, S. (1920). Más allá del principio del placer. Psicología de las masas y análisis del yo. [Tomo XVIII]. Buenos Aires: Amorrortu. Freud, Número 2, Bogotá, 2002.

Gómez, G. (2002). Cuerpo significante y goce. Desde el Jardin de Freud. Número 2, 2002 págs. 68-78

Hulme, P. (2004) Theoretical perspectives on the health problems of adults who experienced childhood sexual abuse. Issues in Mental Health Nursing, $\mathrm{N}^{\circ}$ 25, pp. 339-361. https://doi org/10.1080/01612840490432899

Jaramillo, J. (2011). Pasados y presentes de la violencia en Colombia: Expertos y comisiones de estudio sobre la violencia en Colombia. Bogotá: Editorial Pontificia Universidad Javeriana, 2014.

Lacan, J. (1938). Los complejos familiares en la formación del individuo. [2012] En Otros escritos. Bueno Aires: Paidós.

Lacan, J. (1949) El estadio del espejo como formador de la función del yo [Je] tal como se nos revela en la experiencia psicoanalítica (1949) en: Lacan, J. (2003) Escritos 1, Buenos Aires: Siglo XXI.

Lacan, J. (1951). Algunas reflexiones sobre el yo. Buenos Aires: Paidós.

Lacan, J. (1957): Seminario 5. Las formaciones del inconsciente. Paidós, Buenos Aires, 2003

Lacan, J. (1958 -1959). El Seminario 6. El deseo y su Interpretación. Buenos Aires: Paidós, 2015.

Lacan, J. (1962). La angustia. Buenos Aires: Bueno Aires.

Lacan, J. (1966). Los cuatro conceptos fundamentales del psicoanálisis. [Seminario 11, 1989]. Barcelona: Paidós.

Lacan, J. (1973). El seminario. [Libro 20, Aun (1972-1973) 1988. Buenos Aires: Paidós.

Lacan, J. (1991). El reverso del psicoanálisis. En El Seminario. [Libro 17]. Barcelona:Paidós.

Lacan, J. (2003.). las formaciones del inconsciente. [Seminario 5]. Buenos Aires: Paidós.

Laurent, E. (2007). El caso, de la construcción a la mentira. [en La revue de la ecole de la cause freudienne, 50]. Cuadernos de Psicoanálisis, 26. Recuperado de http://ea.eol.org.ar/03/es/textos/txt/ pdf/el_caso.pdf.

Mesa de trabajo mujer y conflicto armado. (2015). Violencia sociopolitica contra mujeres, jóvenes y niñas en Colombia; Xll informe sobre Violencia sociopolitica contra mujeres, jóvenes y niñas en Colombia. Violencia sexual en el marco del conflicto armado: una mirada diferencial. Recuperado de: http://www.clam.org.br/uploads/ arquivo/XII\%20Informe $\% 20 \mathrm{Mesa} \% 20 \mathrm{Mujer} \% 20 \mathrm{y} \% 20$ Conflicto $\% 20$ Armado.pdf 
Molas, A. (2000). La violencia intrafamiliar como fenómeno social, puntualizaciones sobre la intervención profesional. En Violencia familiar. Montevideo: Creagraf. Recuperado de http://www.edumargen.org/docs/curso30-1/unid02/apunte02_02.pdf

Ortiz, C. (1994). Historiografía de la violencia. Bogotá D.C.: Universidad Nacional de Colombia. Recuperado de http://www.bdigital.unal. edu.co/1429/10/09CAPI08.pdf

Peláez, G. (2011). El sujeto y el lazo social en el psicoanálisis. Psyconex, 4(5). Numero 15 págs.72-84

Piglia, R. (1997). Literatura y psicoanálisis. Recuperado de http://www. elortiba.org/pdf/Piglia_Literatura_y_psicoanalisis.pdf

Reyes, P. (2012). Aplicación de las teorías lacanianas sobre el trauma al tratamiento de pacientes adultos víctimas de abuso sexual en la infan- cia. Un estudio de caso. Recuperado de www.researchgate.net/ publication/235908348_Aplicacion_de_las_teorias_lacanianas_sobre_el_trauma_al_tratamiento_de_pacientes_adultos_ victimas_de_abuso_sexual_en_la_infancia_Un_estudio_de_ caso

Soler C. Lo que queda de la infancia. Medellín. Asociación del campo freudiano. 2014

Velosa, J. (2016, noviembre). Relatos De Violencia: Violencia, Relatos, Psicoanálisis. Ponencia, VIII encuentro internacional infancia y violencia: escenas de un drama. Universidad Nacional de Colombia. En http://www.tramayfondo.com/8-congreso_tyf-actas.html\#comunicaciones 